\title{
How is the Purchase Intention of Consumers Affected in the Environment of E-commerce Live Streaming?
}

\author{
Bojun Lyu ${ }^{1, *}$
}

\author{
${ }^{1}$ Qingdao Academy, Qingdao, Shandong 260071, China \\ 'Corresponding author.Email: lbj210406@163.com
}

\begin{abstract}
Recently, live streaming e-commerce becomes an increasingly popular approach among Chinese consumers and also gets attention from several scholars. In this study, we examine how interactivity between streamers and buyers during live streaming influences the purchase intention. We empirically measure the model by sending questionnaire to people who have shopped via live streaming shopping platforms. The results show that interactivity can influence purchase intention through social presence and telepresence during live streaming, while trust plays a moderating role.
\end{abstract}

Keywords: live streaming, e-commerce, interactivity, trust, presence, purchase intention.

\section{INTRODUCTION}

Nowadays, the fast development of the online market has created more opportunities for electronic commerce. With live streaming becoming more and more prevalent, many stores that live on electronic commerce platforms start to use live streaming as an important way to attract customers and advertise that boosts sales. Gradually, this leads to a new commerce pattern----live streaming shopping. Combined with the era of big data, live streaming of e-commerce has greatly promoted the purchase volume of online shopping. Stemming from 2019 Taobao Live Streaming Ecological Development Report, the live streaming function enabled sellers from Taobao to achieve more than 100 billion Yuan. Live streaming shopping has adapted several aspects from conventional online shopping, there are several main differences. Initially, only can people know the product from fewer pictures and described text. However, sellers could show potential buyers more details about the product through live streaming, customers could know the actual size of the product and how to use the product efficiently, which may maximize the profits[1]. Moreover, before the popularization of live streaming commerce, if customers have questions, they had to contact the sellers by sending messages. Sometimes, customers may receive a reply lately that lower their passion for purchase and sometimes they may not understand what the seller wants to tell through pure words and sentences. Conversely, live streaming allows customers to ask questions via the bullet screen, which sellers can answer these questions timely and explain in videos. Thus, it can benefit both buyers and sellers[15]. Finally, sometimes streamers will close the distance between themselves and the viewers by broadcasting themselves chatting or eating with the audiences. During the live streaming, games will be held to play with visitors or lottery will be organized to increase consumer engagement and achieve the effect of publicity[20].

As an innovative and popular phenomenon, live streaming has been put under the spotlight. Despite the increasing attention on this pattern of shopping, only a few studies have investigated the purchase intention influenced by live streaming [40]. Existing researches on different angles of e-commerce live streaming include consumers' attitudes toward live streaming[43], consumer engagement in live streaming commerce [44], and consumer loyalty toward live-stream shopping[41]. While it is still not clear whether interactivity will positively affect purchase intention online. Thus, we aim to search how live streaming interactivity will influence purchase intentions in social commerce, including the mediating mechanism and the boundary condition.

In order to study the influence of interactivity and other related variables on purchase intention, we first proposed relevant questions and designed questionnaires, which were sent to some large social platforms. Then, we used SPSS24, AMOS24 and other software to collate and analyze the collected data. The 
following is a brief introduction of the basic results: Interactivity has a positive effect on telepresence and social presence; Two presence can also have a positive influence on purchase intention; and Trust positively mediates interaction with telepresence and social presence, respectively. This study mainly brings the following theoretical contributions and management enlightenment to sellers, so as to make better use of live streaming to effectively market their products: The study highlights the significance to manage interactivity, social presence, telepresence and trust in e-commerce platforms. By quoting and extending the model from $\mathrm{Ou}$ et al. [16], the study confirms the importance of moderating trust through interactivity and presence in the achievement of purchase intention. Thus, we conclude that e-commerce live streaming sellers should pay attention to enhancing communication with customers, gaining their sense of trust, and immersing customers in the scene to make them realize their high status as customers, so as to promote their purchase intentions.

The rest of this article is organized as follows. Section 2 describes the literature review, section 3 presents the model of research and purposed hypotheses, section 4 presents data collection and analysis, and finally, section 5 discusses the summary and crucial findings.

\section{LITERATURE REVIEW}

\subsection{Live streaming in social commerce}

Previous e-commerce studies have suggested several prerequisites for consumer behavior [4-6]. This includes platform, content, product, seller, network, and consumer characteristics. Live streaming is a new communication technology, in which users can perceive their own existence through real-time images, pictures and sounds[4]. As a newly popular social media with human-computer interaction, since it has only appeared for decades, there are not many previous studies related to live streaming shopping. However, several newly published articles provide a new perspective for research on live streaming e-commerce[17]. Several studies examined which factors determine the live streaming intention from the perspective of intrinsic motivation and extrinsic motivation of users [45]. Others have studied the effect of design features and customer perception of live streaming on user intention[4].

More and more consumers buy products through live-streaming because it is easy to understand the products they want to buy from different perspectives and ask related questions[19]. Conversely, few scholars have studied how live shopping affects consumers' purchasing intentions. Thus, in the context of live streaming shopping, we have considered several factors that will influence consumer's purchase intention. To be specific, interactivity, perceived social presence and telepresence of consumers and trust can influence consumer's final purchase decision during live streaming.

\subsection{Interactivity}

Interactivity refers to the extent to which users are involved in modifying the form and content of the mediation environment in real time[39]. This is a variable feature of the communication setting. In general, the interaction between buyer and seller can be actively controlled and communicated synchronously. With the increasing understanding of this factor, some scholars have expanded interactivity into three dimensions: active control, two-way communication, and synchronization[39]. Active control measures the degree to which each party actively controls the communication. Synchronization measures the degree of synchronous communication, while two-way communication is the degree of mutual communication[16]. Online shopping platform is a unique form of social media, in which users can interact with sellers and other viewers[45]. Therefore, interactivity embodies the exchange between the audience and the streamer, or exchange between members of the audience watching the same livestream.Researchers have concluded that social interactions drive people to watch infomercial shows. In the context of live streaming e-commerce, the platform's reply, comment, thumb up, click link and other functions improve the relationship between buyers and sellers, which increase purchase intention[24]. Researches on media abundance show that synchronous visual communication enhances the interaction between seller and audience[25]. Therefore, the current study hypothesizes that consumers who expect a higher level of interaction with sellers and other viewers are more likely to engage in live shopping. Studies related to usage behavior show that interactivity influences users' attitude towards social platforms, which in turn influences recommendations and usage intentions[46].

\subsection{Presence}

Presence is defined as the feeling you have in your environment [4]. Presence is the experience of a person's physical environment. It is not human presence in the physical world, but the perception of the environment mediated by automatic and controlled mental processes[48]. To make the research clearer, we divide presence into two parts: telepresence and social presence.

Telepresence is defined as the experience of being in an environment through a communication medium[49]. Compared with presence, telepresence is a more mediated perception of the environment. It provides a 
face-to-face video experience that allows participants to feel that they are in a virtual space instead of the sense of being connected through conventional video communication, and it provides a virtual fusion of image mosaics to achieve a virtual conference room effect. Its sound homophony ensures a real sound field experience. High-resolution accompanying video and physical projection allow participates to send content on computer screens or live objects to share with other participates. In addition, it is characterized by ease of use, configuration of comprehensive meeting control functions, support for multi-party meetings and good compatibility[50].

The definition of social presence is the prominence of others in the interaction and the prominence of the resulting interpersonal relationship[26]. In livestreaming shopping, purchase intention will be influenced when social presence is fulfilled[27]. Researchers in media psychology interpret social presence as the warmth of a medium. Therefore, social presence is the motivation that drives individuals to choose a specific medium. Under the online environment, individuals are not allowed to have humanistic awareness and social ability to interact with other users through online interaction, which has been proved in different scenarios, like online shopping[30] and the use of social media[28]. In the context of live streaming, research has proved that information technology functional support, such as visibility, metavoice and guided shopping, leads to the emergence of a social presence for consumers[3]. Frequent interaction will create a sense of connection between audience and seller[44]. In addition, studies on media abundance show that when sellers acknowledge the existence of viewers by mentioning their existence in the program, the perceived existence of the audience may be enhanced[3].

\subsection{Trust}

The definition of trust is a general belief that the other party in a social exchange will act in an ethically and socially appropriate way and will not engage in opportunistic behavior[32]. It can be seen as a multidimensional concept with three dimensions -benevolence,integrity and competence[51]. In the online marketplace, competence is that the supplier does its job to meet customer expectations, integrity is that the supplier is honest and reliable, and benevolence is that the vendor cares and acts in the best interest of the customer[33]. The trustee is considered trustworthy if all the three factors are high enough[34]. A high level of trust will reduce perceived risk, create a positive attitude and elevate cooperation [51].

Live streaming with potential shopping value (hedonism, utilitarianism or symbolism) may impact customers' attitude and behavior reactions. Trust exists when one party has confidence in the competence, integrity, and kindness of the exchange partner[35]. Online trust includes consumers' perceptions of the site's ability to provide true information and expectations, the company's good intentions, and their impressions of the site's system[1]. Although there have been many studies on trust in both conventional as well as online environments, the majority of them are reflected in seller trust or e-commerce trust. But the relationship between trust and interaction remains uncertain.

\section{CONCEPTUAL MODEL AND HYPOTHESES}

\subsection{Conceptual model}

On the basis of previous studies, we proposed the experimental model for this study (Figure 1). From the model, we demonstrate how interactivity affects social presence and telepresence at live streaming, and how will this influence customer's purchase intention eventually. Now we begin to develop each of our hypotheses. In figure 1, we depict the proposed conceptual model, which reflects the relationship of interactivity and purchase intention, how interactivity influences purchase intention towards social commerce platforms, the mediating effect of social presence and telepresence, and how these two types of presence affect consumer's purchase intentions. In this section, the main components of the conceptual model and their interrelationships are discussed.

\subsection{Interactivity}

In the context of e-commerce shopping, interactivity is the level of participation and communication between buyers and sellers[16]. Telepresence is the feeling of the site that customers can experience through watching live-streaming and interacting with the streamers[49]. There are usually three senses: the sense of human touch, the sense of human concern, and the sense of human sensitivity. As a psychological factor, we believe that interactivity can have a positive impact on people's presence. Firstly, the real-time interactions between customers and sellers during live streaming shopping generate a strong sense of telepresence to customers[50]. In the process of e-commerce live streaming, customers can raise questions related to commodities to the streamer, and the streamer can introduce and answer relevant questions remotely. Therefore, customers can have a more comprehensive understanding of commodities, feel the existence of commodities and feel satisfied, that is, telepresence. When the buyers feel that they have a lot of control over the live-streaming platform and can browse the content freely, the buyers will be more immersed in the virtual world, while the sellers actively promote two-way communication and give the audience the opportunity to 
ask questions to themselves, so that the audience can know more about the products and even the streamers themselves. The fact that sellers respond to messages promptly reinforces the viewer's sense that they are part of the seller's world. Thus, we can hypothesize that:

\section{H1a. Interactivity positively affects telepresence.}

Besides, social presence refers to the perception and connection between the audience and the seller, which helps them to establish closer relationships when watching the live-streaming of e-commerce [26]. When consumers watch e-commerce live streaming with many audiences, they interact with the sellers in a two-way way. When the streamers communicate with customers online, they can have the feeling of chatting with others in real-time, and feel the connection with others and humanistic care[39]. For active control, when buyers feel that they have a lot of control over the livestreaming platform and can browse the content freely, they will feel that their value is improved and they will feel more in touch with the sellers. For two-way communication, the streamer will promote two-way communication and give the audience the opportunity to ask questions, which greatly improves the opportunity for buyers to obtain information and feel humanistic care. And for synchronicity, the fact that sellers respond to messages on time reinforces the buyer's human sensitivity. Thus, we can hypothesize that:

H1b. Interactivity positively affects social presence.

\subsection{Presence}

\subsubsection{Telepresence}

For telepresence, viewers may feel immersed in the world of the broadcaster rather than the real world. When audiences watch live streaming of e-commerce, they feel like they are immersed in the world of the streamer. As a result, people will have a higher inclination to purchase the products. If audiences feel like they are more in the real world than the virtual world when watch live streaming of e-commerce, their purchase intention will be lower. The telepresence in online shopping environments can make customers feel comfortable[49]. That's because positive feelings can make it easier for customers to make purchase decisions. Customers with higher telepresence reduce the uncertainty of products because they will get more product information[50], and then customers' confidence in making purchase decisions is also enhanced[49]. Therefore, people will be more willing to buy and we can hypothesize that

H2a. Telepresence positively affects purchase intention.

\subsubsection{Social presence}

Firstly, a social website can deliver more information to customers, thus increasing the perceived transparency of customers[52]. The stronger the social presence of a platform, the more information customers can grasp, thus improving the transparency of customers' perception. The more transparent the shopping environment is, the safer consumers will feel when deciding to buy products[9]. Secondly, social presence can shorten the psychological distance between customers and sellers to help them build a closer connection[9]. Therefore, social presence brings customers and sellers closer, and we propose a hypothesis that:

$\mathrm{H} 2 \mathrm{~b}$. Social presence positively affects purchase intention.

\subsection{Trust}

The concept of trust is a belief that the buyer believes that the seller is trustworthy and will provide excellent service without using false information to deceive them, while the customers believes that the products will satisfy their expectations and that it will look and function as the seller says[53]. Trust exerts an important influence on consumers' purchase decisions[40] and promotes the interactions between streamers and consumers in live streaming ecommerce[1]. Trust can lead consumers to generate positive moods and alleviate the effect of risks. During the live streaming, the interactivity between sellers and buyers has solidified their bond, and their trust will reinforce their perceived presence. When the trust between the buyer and the live e-commerce becomes higher, the relationship between interactivity and telepresence will be strengthened since people are more likely to chat and interact with streamers when they trust them, so buyers will feel more immersive in the virtual world. By contrast, when the trust between the buyer and the live e-commerce becomes lower, consumers will no longer enjoy interacting with sellers. They will have a stronger sense of strangeness to the product, so the telepresence will be curtailed. Thus, we can hypothesize that:

H3a. Trust will strengthen the positive relationship between interactivity and telepresence.

When the degree of trust between buyers and sellers is high, customers will be more willing to communicate with sellers. Both sides feel the existence of each other psychologically when they share the same room for face-to-face. Therefore, trust reinforces the bond between interactivity and trust. On the contrary, when the degree of trust between buyers and sellers is low, the relationship between interactivity and social presence will be less stable. If buyers don't really trust and 
appreciate the seller, they would not concentrate on watching the live streaming and chatting with the seller. Due to the lack of language communication, the two sides will not feel intimate but will regard it as a simple business relationship. Therefore, social presence has been hindered. Thus, we can hypothesize that:

H3b. Trust will strengthen the positive relationship between interactivity and social presence.

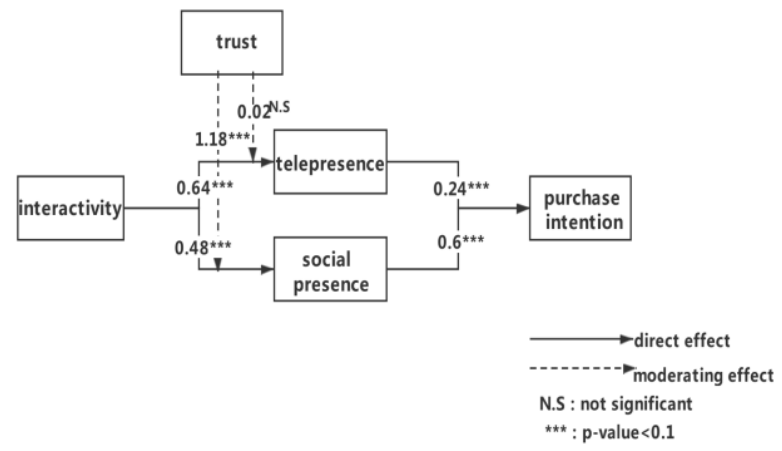

Figure 1 Conceptual model

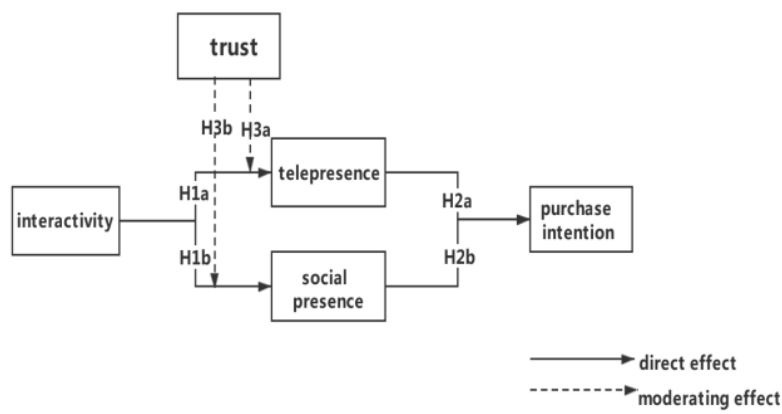

Figure 2 Structural model of interactivity behavior in live streaming

\section{DATA COLLECTION AND ANALYSIS}

\subsection{Data collection}

Our research focused on social commerce and social media platforms with live shopping capabilities. We mainly consider Taobao, Jingdong, Douyin, Kuaishou, which are the four largest Chinese e-commerce platforms with the functions of live streaming shopping on their websites. In terms of Taobao and Jingdong, their main functions are providing a place for customers to shop online and numerous stores provide products and services. Douyin and Kuaishou became popular recently among young people in China, which are short video playback platforms. All questionnaires are online, generated by the Wenjuanxing website, one of the largest Chinese professional data collection websites. For the consistency between the originals and our questions, we translated them into Chinese and designed the questionnaire for our study. For the consistency between the Chinese and English originals, we confirmed it by the sougou translation check. Then, customers were instructed to answer the questions based on their previous experiences. Eventually, we received 278 responses in total. Of those responses, 14 were excluded because of inappropriate data. A final sample of 264 valid responses was analyzed by us. Respondent demographics are presented in Table 1.

\subsection{Measures}

All measures in this study have been used and validated in prior studies. We also made a little bit of adjustment to fit the current research context. We designed interactivity as our independent variable, purchase intention as our dependent variable. Telepresence and social presence are used to be intervening variables linked between interactivity and purchase intention. Finally, we took trust as the moderating variable that calculated by SPSS 24 . To be specific, interactivity was measured after the adaption from Liu [39], and divided into active control, two-way communication, and synchronicity; trust was measured with the items adapted from Lu et al.[2] and divided into 4 items; telepresence came from Wei et al. [49] and social presence derived from Lu et al. [54], both of them are divided into three items. Finally, purchase intention was adapted from Sun et al. [9]. Instruments for all the constructs were phrased on a 7-point Likert scale, anchored from " $1=$ strongly disagree" to " $7=$ strongly agree". We designed questions to know about respondent's age, gender, educational level as well as multiple choices like the platforms they watch and types of products they are fond of.

\subsection{Simple characteristics}

Table 1 demonstrates the demographic statistics. To be specific, about $62.1 \%$ of the testers were male, and the other $37.9 \%$ were female. As the target customers who use the online commerce applications are mainly youngsters and middle-aged workers, people aged between 18 and 40 were about $80 \%$, and most of them were undergraduate $(66.7 \%)$, accounting for an overwhelming majority of respondents. Moreover, most of them have used more than one online commerce application, and among all the platforms, Taobao and DouYin are more popular than others. Concerning the types of products they bought, we divided all the products into two major categories: search good and experience good. $59.8 \%$ of products are search good and $40.2 \%$ of products are experiment good.

\subsection{Data analysis and results}

A total of 15 items were used to measure these 5 constructs. The items were modified according to the relevant research to ensure that they were appropriate to the topic and context of the study, thus ensuring the content validity of the measured items. Before formal 
hypothesis examining, we examined the reliability and validity of the measurement items and analyzed the data using SPSS 24 and AMOS 24.[36]

\subsubsection{Measurement model}

According to Table 2, Cronbach's alpha and Composite Reliability (CR) were used to test our model's reliability. The Cronbach's alpha values were between 0.79 and 0.93 , and $C R$ values were ranged from 0.84 to 0.93 . A Cronbach's $\alpha$ that $\geq 0.7$ is acceptable and means highly reliable as it shows a close correlation between items[37] and a CR that $\geq 0.7$ indicates high reliability [38]. Thereby, both values surpass the standard of 0.7 , which means that the model has accorded with reliability requirements. Besides, the average variance extracted (AVE) was used to test the convergent validity, and AVE values of all constructs were between 0.55 to 0.79 , which exactly exceed the accepted level of 0.5 that can be resulted from measurement error. As a result, the convergent validity is also satisfied.

\subsubsection{Structural model}

After examined the reliability as well as validity, we used structural equation modeling (SEM ) to confirm the hypothesis as SEM can be used to calculate several latent variables[36]. The results of the analysis are presented in Figure 2 and Table 4, including the standardized path coefficients $(\beta)$ and the significance level of each path. According to the table4, Absolute fit is examined by relative chi-square (CMIN/DF) and root means the square error of approximation (RMSEA). We already know that a relatively small value of CMIN/DF denotes a better model fit, and the value between 1 and 5 are acceptable[3], and the RMSEA that $<0.08$ shows a good fit either[55]. Besides, the comparative fit index (CFI) can be measured for comparative fit. A CFI of > 0.90 is well acceptable[3]. The overall fit of this model is roughly adequate $(\mathrm{CMIN} / \mathrm{DF}=1.743$, NFI $=0.45$, $\mathrm{CFI}=0.464$, RMSEA=0.075). According to figure 2, we used AMOS 24 to detect the mediate effects, which illustrates that the p-values of all current hypotheses (H1-H3) are less than 0.01 , except $\mathrm{H} 3 \mathrm{a}$, and only $\mathrm{H} 3 \mathrm{a}$ is not significant. Thus, we can conclude that nonresponse bias won't be too crucial to affect the final results.

Table 1 Demographic information of respondents

\begin{tabular}{|c|c|c|c|}
\hline Measure & Item & Count & $\%$ \\
\hline \multirow{2}{*}{ Gender } & Male & 164 & 62.1 \\
\hline & Female & 100 & 37.9 \\
\hline \multirow[t]{5}{*}{ Age } & $<18$ & 24 & 9.1 \\
\hline & $18-30$ & 126 & 47.7 \\
\hline & $31-40$ & 86 & 32.6 \\
\hline & $41-50$ & 14 & 5.3 \\
\hline & $>50$ & 14 & 5.3 \\
\hline \multirow[t]{4}{*}{ Educational-level } & senior high school & 56 & 21.2 \\
\hline & undergraduate & 176 & 66.7 \\
\hline & master & 30 & 11.4 \\
\hline & doctor & 2 & 0.8 \\
\hline \multirow[t]{5}{*}{ Platform } & taobao & 162 & 61.4 \\
\hline & Jingdong & 64 & 24.2 \\
\hline & douyin & 112 & 42.4 \\
\hline & kuaishou & 36 & 13.6 \\
\hline & others & 42 & 15.9 \\
\hline \multirow[t]{12}{*}{ types of product } & search good & 158 & 59.8 \\
\hline & experience good & 106 & 40.2 \\
\hline & home appliances & 48 & 18.2 \\
\hline & digital product & 64 & 24.2 \\
\hline & computer(accessory) & 50 & 18.9 \\
\hline & book & 104 & 39.3 \\
\hline & aduio equipment & 14 & 5.3 \\
\hline & virtual currency & 4 & 1.5 \\
\hline & commodity & 140 & 58.0 \\
\hline & clothing and shoe & 188 & 71.2 \\
\hline & food/nutrition & 118 & 44.7 \\
\hline & cosmetic/jewelry & 122 & 46.2 \\
\hline
\end{tabular}


Table 2 Reliability and convergent validity analysis

\begin{tabular}{|c|c|c|c|c|c|c|}
\hline Constructs & Item & Mean & S.D. & Cronbach & CR & AVE \\
\hline \multirow[t]{2}{*}{$\begin{array}{c}\text { Interactivity-activate- } \\
\text { control }\end{array}$} & $\mathrm{IA} 1$ & 4.04 & 1.384 & 0.88 & 0.881 & 0.56 \\
\hline & IA2 & 4.7 & 1.336 & & & \\
\hline \multirow[t]{2}{*}{$\begin{array}{l}\text { Interactivity two-way } \\
\text { communication }\end{array}$} & IT1 & 4.61 & 1.215 & & & \\
\hline & IT2 & 4.55 & 1.187 & & & \\
\hline \multirow[t]{2}{*}{$\begin{array}{l}\text { Interactivity } \\
\text { synchronicity }\end{array}$} & IS1 & 4.25 & 1.268 & & & \\
\hline & IS2 & 4.34 & 1.241 & & & \\
\hline \multirow[t]{4}{*}{ Trust } & TR1 & 4.08 & 1.179 & 0.93 & 0.934 & 0.782 \\
\hline & TR2 & 4.14 & 1.158 & & & \\
\hline & TR3 & 4.17 & 1.160 & & & \\
\hline & TR4 & 3.89 & 1.231 & & & \\
\hline \multirow[t]{3}{*}{ Social presence } & SP1 & 4.17 & 1.193 & 0.887 & 0.888 & 0.726 \\
\hline & SP2 & 3.84 & 1.151 & & & \\
\hline & SP3 & 4.02 & 1.217 & & & \\
\hline \multirow[t]{3}{*}{ Telepresence } & TE1 & 3.92 & 1.266 & 0.79 & 0.849 & 0.671 \\
\hline & TE2 & 3.85 & 1.269 & & & \\
\hline & TE3 & 4.2 & 1.298 & & & \\
\hline \multirow[t]{3}{*}{ Purchase intention } & PI1 & 3.65 & 1.308 & 0.908 & 0.92 & 0.794 \\
\hline & $\mathrm{PI} 2$ & 4.02 & 1.204 & & & \\
\hline & PI3 & 4.08 & 1.270 & & & \\
\hline
\end{tabular}

Table 3 Latent variable correlations

\begin{tabular}{cccccc}
\hline & IN & TR & SP & TE & PI \\
\hline Interactivity(IN) & 0.748 & & & & \\
Trust(TR) & 0.644 & 0.819 & & & \\
Social presence(SP) & 0.802 & 0.919 & 0.852 & & \\
Telepresence(TE) & 0.645 & 0.752 & 0.821 & 0.891 \\
Purchase intention(PI) & 0.647 & 0.486 & 0.674 & 0.567 & 0.884 \\
\hline
\end{tabular}

Table 4 Model fit

\begin{tabular}{ccccc}
\hline CMIN & CMIN/DF & NFI & CFI & RMSEA \\
\hline 256.29 & 1.743 & 0.45 & 0.464 & 0.075 \\
\hline
\end{tabular}




\section{CONCLUSION}

\subsection{Implications}

Our study has examined the role of different factors in live streaming, which is one of the newest sale approaches for electronic commerce sellers. Its real-time trait brings consumers a distinctive shopping experience that overcomes the defects of traditional online shopping. Our study discusses how interactivity affects purchase intention. To do this, we designed a research model that demonstrates the mediating role of telepresence and social presence between interactivity and purchase intention and the moderating role of trust. Since presence is not fully explored in different contexts, we studied the presence of the live streaming shopping in the model and examined it as the mediating variable. Moreover, the research examined whether trust will moderate the relationship between interactivity and presence. Our results show that presence has a significant impact on online shopping and actively improves customer's purchase intention. And trust will strengthen the impact of interactivity on presence.

\section{2. limitations and suggestions}

Our research also has some limitations. First of all, the base of our respondents is not large, and there are strangers answering questions, so it is impossible to guarantee that the respondents' answers are consistent with the actual situation. The majority of the results we received were under 18 , and 30 and older. The future research could enlarge the scope of respondents and reexamine the results. Second, we only studied the effects of interactivity on telepresence and social presence, since there is a close relationship between intention and actual behavior. However, actual behavior is not the same as intention, and future researches could examine how trust affects actual behavior.

\section{References}

[1] Wongkitrungrueng, A., Assarut, N., Business, J. O., \& Woodside, A. G. (2020). The role of live streaming in building consumer trust and engagement with social commerce sellers.

[2] Lu Y, Ling Z, Wang B. From virtual community members to $\mathrm{C} 2 \mathrm{C}$ e-commerce buyers: Trust in virtual communities and its effect on consumers' purchase intention[J]. Electronic Commerce Research \& Applications, 2010, 9(1-6):346-360.

[3] Ma Y. To shop or not: Understanding Chinese consumers' live-stream shopping intentions from the perspectives of uses and gratifications, perceived network size, perceptions of digital celebrities, and shopping orientations -
ScienceDirect[J]. Telematics and Informatics, 2021, 59.

[4] Chen C C, Lin Y C. What drives live-stream usage intention? The perspectives of flow, entertainment, social interaction, and endorsement[J]. Telematics \& Informatics, 2018, 35(1):293-303.

[5] Bao H, Li B , Shen J, et al. Repurchase intention in the Chinese e-marketplace: Roles of interactivity, trust and perceived effectiveness of e-commerce institutional mechanisms[J]. Industrial Management \& Data Systems, 2016, 116(8):17591778 .

[6] Cheng X, Gu Y, J Shen. An integrated view of particularized trust in social commerce: An empirical investigation[J]. International Journal of Information Management, 2019, 45:1-12.

[7] Ma Y. To shop or not: Understanding Chinese consumers' live-stream shopping intentions from the perspectives of uses and gratifications, perceived network size, perceptions of digital celebrities, and shopping orientations ScienceDirect[J]. Telematics and Informatics, 2021, 59.

[8] Dan J K, Ferrin D L, Rao H R. A Trust-Based Consumer Decision-Making Model in Electronic Commerce: The Role of Trust, Perceived Risk, and Their Antecedents[J]. Decision Support Systems, 2008, 44(2):544-564.

[9] Sun Y, Shao X, Li X, et al. How Live Streaming Influences Purchase Intentions in Social Commerce: An IT Affordance Perspective[J]. Electronic Commerce Research and Applications, 2019, 37:100886.

[10] Hu M, Zhang M, Wang Y. Why do audiences choose to keep watching on live video streaming platforms? An explanation of dual identification framework[J]. Computers in Human Behavior, 2017, 75(oct.):594-606.

[11] Taobangdan, Taobao Live Streaming, 2019. 2019 Taobao Live Streaming Ecological Development Report.

[12] Wongkitrungrueng, A., Assarut, N., 2018. The role of live streaming in building consumer trust and engagement with social commerce sellers. J. Bus. Res.

[13] Kim, S., Park, H., 2013. Effects of various characteristics of social commerce (s-commerce) on consumers' trust and trust performance. Int. J. Inform. Manage. 33 (2), 318-332. 
[14] Zhou, L., Wang, W., Xu, J., Liu, T., Gu, J., 2018. Perceived information transparency in B2C ecommerce: an empirical investigation. Inform. Manage. 55 (7), 912-927.

[15] Chen, A., Lu, Y., Wang, B., 2017. Customers' purchase decision-making process in social commerce: a social learning perspective. Int. J. Inform. Manage. 37 (6), 627-638.

[16] Ou, C.X., Pavlou, P.A., Davison, R., 2014. Swift guanxi in online marketplaces: the role of computer-mediated communication technologies. MIS Q. 38 (1), 209-230.

[17] Cai, J., Wohn, D.Y., Mittal, A., Sureshbabu, D., 2018. Utilitarian and hedonic motivations for live streaming shopping, In: Proceedings of the 2018 ACM International Conference on Interactive Experiences for TV and Online Video, Seoul, Republic of Korea, pp. 81-88

[18] Ho, C.-T., Yang, C.-H., 2015. A study on behavior intention to use live streaming video platform based on TAM model, In: The Fifth Asian Conference on Psychology and Behavioral Sciences Osaka, Japan, pp. 1-20

[19] Lu, Z., Xia, H., Heo, S., Wigdor, D., 2018. You watch, you give, and you engage: a study of live streaming practices in China, In: 2018 ACM CHI Conference on Human Factors in Computing Systems, Montreal, QC, Canada, pp. 1-13.

[20] Hilvert-Bruce, Z., Neill, J. T., Sjöblom, M., \& Hamari, J. (2018). Social motivations of live streaming viewer engagement on Twitch. Computers in Human Behavior, 84, 58-67.

[21] Cai, J., Wohn, D. Y., Mittal, A., \& Sureshbabu, D. (2018, June). Utilitarian and hedonic motivations for live streaming shopping (Chairs) In H. Ryu, J. Kim, \& T. Chambel(Eds.). Proceedings of the 2018 ACM international conference on interactive experiences for TV and online video (pp. 81-88). New York, NY: Association for Computing Machinery.

[22] Gumpert, G., Drucker, S.J., 1992. From the agora to the electronic shopping mall. Crit. Stud. Media Commun. 9 (2), 186-200.

[23] Olbrich, R., Holsing, C., 2011. Modeling consumer purchasing behavior in social shopping communities with clickstream data. Int. J. Electron. Commerce. 16 (2), 15-40.

[24] Wang, C., Zhou, Z., Jin, X.L., Fang, Y., Lee, M.K., 2017. The influence of affective cues on positive emotion in predicting instant information sharing on microblogs: Gender as a moderator. Inf. Process. Manage. 53 (3), 721-734.

[25] Liao, G.Y., Huang, T.L., Cheng, T.C.E., Teng, C.I., 2020. Impacts of media richness on network features and community commitment in online games. Industrial Management \& Data Systems.

[26] Short, J., Williams, E., \& Christie, B. (1976). The social psychology of telecommunications. Hoboken, NJ: John Wiley \& Sons.

[27] Hou, F., Guan, Z., Li, B., Chong, A.Y.L., 2019. Factors influencing people's continuous watching intention and consumption intention in live streaming. Internet Res.

[28] Gan, C., Li, H., 2018. Understanding the effects of gratifications on the continuance intention to use WeChat in China: A perspective on uses and gratifications. Comput. Hum. Behav. 78, 306-315.

[29] Kim, Y., Jun, J.W., 2020. Factors Affecting Sustainable Purchase Intentions of SNS Emojis: Modeling the Impact of Self-Presentation. Sustainability 12 (20), 8361.

[30] Dash, S., Saji, K.B., 2008. The role of consumer self-efficacy and website social-presence in customers' adoption of B2C online shopping: an empirical study in the Indian context. J. Int. Consumer Market. 20(2), 33-48.

[31] Tseng, F.C., Cheng, T.C.E., Yu, P.L., Huang, T.L., Teng, C.I., 2019. Media richness, social presence and loyalty to mobile instant messaging. Industrial Management \& Data Systems

[32] Gefen, D., Karahanna, E., and Straub, D. W. Inexperience and experience with online stores: the importance of TAM and trust. IEEE Transactions on Engineering Management, 50, 3, 2003a, $307-$ 321.

[33] McKnight, D. H., Choudhury, V., and Kacmar, C. The impact of initial consumer trust on intentions to transact with a web site: a trust bui

[34] Mayer, R. C., Davis, J. H., and Schoorman, F. D. An integrative model of organizational trust. Academy of Management Review, 20, 3, 1995, 709-734.

[35] Gefen, D., and Straub, D. W. Consumer trust in B2C e-commerce and the importance of social presence: experiments in E-products and Eservices. Omega: The International Journal of Management Science, 32, 6, 2004, 407-424

[36] Bollen, K.A., 1989. A new incremental fit index for general structural equation models. Sociol. Methods Res. 17(3), 303-316. 
[37] Fornell, C., Larcker, D.F., 1981. Evaluating structural equation models with unobservable variables and measurement error. J. Market. Res.18(1), 39-50.

[38] Hair Jr., J.F., Black, W.C., Babin, B.J., Anderson, R.E., 2010. Multivariate data analysis: A global perspective, 7th ed. Pearson Education International.

[39] Liu, Y. (2003). Developing a scale to measure the interactivity of websites. Journal of Advertising Research, 43(2), 207-216.

[40] Yu, E., Jung, C., Kim, H., Jung, J., 2018. Impact of viewer engagement on gift-giving in

live video streaming. Telemat. Inform. 35 (5), 14501460.

[41] Hsu C L, Lin C C, Miao Y F . Why Are People Loyal to Live Stream Channels? The Perspectives of Uses and Gratifications and Media Richness Theories[J]. CyberPsychology \& Behavior, 2020, 23(5):351-356.

[42] https://www.wjx.cn/

[43] Park, H. J., and L. M. Lin. "The effects of matchups on the consumer attitudes toward internet celebrities and their live streaming contents in the context of product endorsement." Journal of Retailing and Consumer Services 52(2020).

[44] Hu, M., and S. S. Chaudhry. "Enhancing consumer engagement in e-commerce live streaming via relational bonds." Internet Research ahead-ofprint.ahead-of-print(2020).

[45] Zhao, Q., et al. "Determinants of live streamers' continuance broadcasting intentions on Twitch: A self-determination theory perspective." Telematics and Informatics (2018):406-420.

[46] Curras-Perez, et al. "How social, environmental, and economic CSR affects consumer-perceived value: Does perceived consumer effectiveness make a difference?." Corporate Social Responsibility \& Environmental Management (2018).

[47] Jia, Y., et al. "Impact of mobile instant messaging applications on signaling load and UE energy consumption." Wireless Networks 23.5(2017):110 .

[48] Gibson, J. J. "The Ecological Approach to Visual Perception." The ecology rotarik remarks 42.1(1979):98-99.

[49]Wei Gao, Xue Li. "Building presence in an online shopping website: the role of website quality", Behaviour \& Information Technology, 2018
[50] MM Agócs, Serhan, F. , Yen, C. , Mwenda, J. M. , \& Kang, G. . (2014). Who global rotavirus surveillance network: a strategic review of the first 5 years, 2008-2012. Wkly Epidemiol Rec, 63(29), 340-344.

[51] e-journal.uajy.ac.id

[52] Bastide, P. R., F. Lu, and A. A. Mahmoud. "INTELLIGENTLY SPLITTING TEXT IN MESSAGES POSTED ON SOCIAL MEDIA WEBSITE TO BE MORE READABLE AND UNDERSTANDABLE FOR USER." (2016).

[53] Wang, H., and Y. Lu. "Trust governance based on active interpersonal strategy." Nankai Business Review International (2010).

[54] Lu, B., W. Fan, and M. Zhou . "Social presence, trust, and social commerce purchase intention: An empirical research." Computers in Human Behavior 56.Mar.(2016):225-237.

[55] repub.eur.nl 